\title{
ETHzürich
}

ETH Library

\section{Rheology of nanofibrillated cellulose/acrylate systems for coating applications}

\author{
Journal Article \\ Author(s): \\ Grüneberger, Franziska; Künniger, Tina; Zimmermann, Tanja; Arnold, Martin \\ Publication date: \\ 2014-06 \\ Permanent link: \\ https://doi.org/10.3929/ethz-b-000085296 \\ Rights / license: \\ In Copyright - Non-Commercial Use Permitted \\ Originally published in: \\ Cellulose 21(3), https://doi.org/10.1007/s10570-014-0248-9
}




\title{
Rheology of nanofibrillated cellulose/acrylate systems for coating applications
}

\author{
Franziska Grüneberger • Tina Künniger • \\ Tanja Zimmermann • Martin Arnold
}

Received: 11 December 2013/Accepted: 20 March 2014/Published online: 27 March 2014

(C) Springer Science+Business Media Dordrecht 2014

\begin{abstract}
In this work, the suitability of nanofibrillated cellulose (NFC) as a novel component for wood coatings has been evaluated. NFC was prepared from two different wood pulps with a high pressure homogeniser and a grinder, depending on the initial fibre size of the two pulps. The fibrillation process was monitored using viscosity measurements and scanning electron microscopy. Viscosity measurements were found to be a suitable, reliable and especially fast and easy method for process monitoring, optimization and quality assessment of the NFC fibrillation process. NFC was mixed with four different waterborne acrylic polymer emulsions and analysed regarding its rheological behaviour. The viscosity of the acrylate-NFC suspensions was dominated by the NFC, whereas the polymer type was of minor importance at the tested concentrations. The viscosity increased exponentially after NFC addition and consequently the viscosity of such suspensions would be precisely adjustable in the considered shear range. During accelerated storage at elevated temperatures, the general flow behaviour did not change; only a slight viscosity increase was observed. The study shows that rheology is an important issue that has to be taken into account when
\end{abstract}

F. Grüneberger $(\bowtie) \cdot$ T. Künniger · T. Zimmermann · M. Arnold

Applied Wood Materials, Swiss Federal Laboratories for

Materials Science and Technology (Empa),

Ueberlandstrasse 129, 8600 Dübendorf, Switzerland

e-mail: Franziska.Grueneberger@empa.ch applying NFC as additive in water based coating systems and that NFC is suitable as component for coating applications.

Keywords Nanofibrillated cellulose · Rheology · Acrylate emulsion · Waterborne · Coating application

\section{Introduction}

When used for outdoor applications, the biomaterial wood is exposed to UV radiation, rain and humidity, mechanical impacts and microorganisms (Wicks et al. 2006). All these effects can degrade the wood surface, decrease its durability and change its appearance. Protective coatings are thus necessary to avoid premature and expensive maintenance. Main components of coatings are polymeric binders among which waterborne polymer emulsions such as acrylates are attracting more and more interest (Philipp 2010). The trend to waterborne systems is obvious, as toxic volatile organic components (VOC) and thus flammability are reduced and more environmentally friendly products are produced.

The performance and durability of organic wood coatings is expected to be improved by nanofibrillated cellulose (NFC) as novel additive, which would act as mechanically reinforcing component and as carrier for functional agents such as UV absorbers or antimicrobials. 
Nanofibrillated cellulose and other nanocelluloses have already been reported widely as reinforcing components for polymers (Dufresne 2012). Using nanocelluloses is attractive because of their beneficial properties: they exhibit excellent mechanical performance at low weight, are biocompatible, transparent and reactive due to the hydroxyl groups on their large fibre surfaces (Klemm et al. 2011). Nanocelluloses derive from cellulose, a renewable, biodegradable and the most abundant biopolymer on earth. NFC has already been isolated from many different cellulose materials such as wood pulp, hemp, sugar-beet pulp and others (Zimmermann et al. 2010; Helbert et al. 1996; Agoda-Tandjawa et al. 2010). The first isolation of NFC from wood cellulose pulp was carried out with a homogenizer and was described by Turbak et al. (1983). Nowadays, different mechanical isolation procedures have been established. High-shear homogenizers and grinders are the most favoured methods (Zimmermann et al. 2004; Iwamoto et al. 2005). In addition, chemical or enzymatic pre-treatments of cellulose pulps were introduced to shorten the isolation process and to minimize energy consumption (Saito et al. 2006; Pääkkö et al. 2007). In such ways, fibres with diameters between 5 and $100 \mathrm{~nm}$ and lengths of more than $1 \mu \mathrm{m}$ are produced.

For the preparation of nanocellulose nanocomposites, a wide range of polymers has already been tested, e.g., polylactic acid, hydroxypropyl cellulose, polyvinylacetate, polyacrylate latices and epoxy resin (Favier et al. 1995; Ruiz et al. 2001; Tingaut et al. 2010; LopezSuevos et al. 2010). Different applications of such nanocomposites were proposed and examined, e.g., in biomedicine, for packaging materials and for electronic displays (Eyholzer et al. 2011; Ho et al. 2012; Yano et al. 2005). Few researchers also mentioned the potential use of nanocelluloses in coating materials and examined NFC containing coatings for the paper and packaging industry (Ruiz et al. 2001; Cavaille et al. 2000; Martins et al. 2012; Ridgway and Gane 2012; Aulin and Ström 2013). There, the addition of NFC targets material improvements related to barrier, antimicrobial and mechanical properties and processing characteristics. However, reports on using nanocelluloses in wood coatings are rare. Landry and Blanchet (2009) used silane modified nanocrystalline cellulose to produce hydrophobic wood coatings and Jämsä et al. (2010) used NFC to achieve a better distribution of nanoparticles within wood coatings.
Apart from the mentioned functions of NFC in coatings, rheological effects are very important for coating processing and application. For instance, a higher viscosity is required for roller coating than for spray coating applications and a too high viscosity would cause insufficient levelling of the coating on the substrate (Bulian and Graystone 2009).

The first rheological study on NFC was published in the pioneering works by Herrick et al. (1983), who described the shear thinning behaviour of a suspension of $2 \%(\mathrm{w} / \mathrm{w})$ NFC in water. This has been explained later by the breakdown and the change of the inner structure of NFC suspensions (Iotti et al. 2011; Karppinen et al. 2012). It is also well known that NFC suspensions exhibit higher viscosities with advanced fibrillation grade or increasing NFC concentration (Saito et al. 2006; Saarikoski et al. 2012). During fibrillation, the surface area increases and therefore more interactions between fibres and fibril aggregates, considered as flocs, are possible, which leads to higher resistance to flow. The influence of temperature, $\mathrm{pH}$ and salts on the flowing properties of NFC suspensions was further investigated. By changing the temperature, only slight viscosity changes were monitored. However, the viscosity increased at decreasing $\mathrm{pH}$ or increasing salt concentration due to the reduction of interfibrillar, electrostatic repulsion at higher hydrogen ion or salt concentration (Pääkkö et al. 2007; Agoda-Tandjawa et al. 2010). Moreover, low amounts of water-soluble polymers such as sodium carboxymethylcellulose and sodium polyacrylate were added to nanocellulose suspensions (Lowys et al. 2001; Boluk et al. 2012). There, the viscosity of a suspension of cellulose nanocrystals (CNC) with Newtonian flow behaviour was increased and changed to shear thinning flow after polymer addition.

To our knowledge, only two reports exist about viscosity measurements of polymer emulsions containing nanocellulose materials. Ruiz et al. (2001) described a suspension of a waterborne epoxy polymer emulsion and $\mathrm{CNC}$ designated for coatings without mentioning a specific application. The nanocrystals significantly increased the viscosity compared to the neat epoxy emulsion at low shear rates. At higher shear rates $(100 \mathrm{l} / \mathrm{s})$ the viscosity was nearly the same for the neat polymer emulsion and the polymer-CNC suspension. Bousfield et al. (2013) prepared suspensions containing NFC, carboxylated styrene-butadiene latex and kaolin clay. They showed increasing 
viscosities with increasing amounts of NFC at constant polymer and kaolin contents and the suspensions had the typical shear thinning behaviour of neat NFC suspensions. However, until now, no information about the rheology of NFC and acrylate suspensions is available.

Aim of this work was therefore to investigate changes of rheological properties of water-borne acrylate suspensions by the addition of NFC, with regard to coating applications.

\section{Materials and methods}

Materials

Two never dried cellulose raw materials were chosen, namely a refined fibrous beech wood pulp with $79 \%$ cellulose content, $14 \%$ hemicelluloses and $0.8 \%$ rest lignin (Arbocel ${ }^{\circledR}$, J. Rettenmeier \& Söhne GmbH\&Co. $\mathrm{KG}$, Germany) and a totally chlorine-free softwood kraft pulp with $81 \%$ cellulose content, $14 \%$ hemicelluloses and $1.5 \%$ rest lignin (TCF, Zellstoff Stendal, Germany). The chemical composition of the pulps was determined according to TAPPI standards. Four different commercially available binders in form of acrylate polymer emulsions were selected to prepare the acrylate-NFC suspensions. Table 1 presents the four polymer emulsions including their suppliers and their properties as declared by the suppliers. The additives used and their corresponding suppliers are included in Table 2.

Fibrillation of cellulose raw materials

The two cellulose raw materials were fibrillated by using different mechanical processes, which are schematically shown in Fig. 1. The beech wood pulp was suspended in deionized water to obtain a suspension of $1.5 \%(\mathrm{w} / \mathrm{w})$ concentration. The suspension was continuously stirred at $10{ }^{\circ} \mathrm{C}$ for at least 4 days to enable swelling. The swollen pulp was treated in an inline dispersing system (Megatron MT 3000, Kinematica AG, Switzerland) at $16,000 \mathrm{rpm}$ for $25 \mathrm{~min} / \mathrm{kg}$ suspension. Then, the suspension was processed in a high pressure homogenizer (Microfluidizer ${ }^{\circledR}$, Microfluidics Corporation, USA) with two interaction chamber combinations and pressures up to 1,200 bar. First, the suspension was passed 10 times through chambers with diameters of 400 and $200 \mu \mathrm{m}(\mathrm{H} 230 \mathrm{z}, \mathrm{H} 30 \mathrm{z})$. Afterwards, the suspension was diluted to $1.3-1.4 \%(\mathrm{w} / \mathrm{w})$ due to viscosity increase and then was passed 10 times through chambers with diameters of 200 and $75 \mu \mathrm{m}$ (H30z, F20y). The resulting NFC material is further named NFC1.

The softwood pulp was first disintegrated in a grinder (Supermasscolloider MKZA 10-20 J CE,

Table 2 Standard formulations of acrylate-NFC1 suspensions with $0.25 \%$ (w/w) NFC content

\begin{tabular}{|c|c|c|c|c|}
\hline \multirow[t]{2}{*}{ Component } & \multicolumn{4}{|c|}{ Content in suspension [\%] } \\
\hline & Acr1 & Acr2 & Acr3 & Acr4 \\
\hline $\begin{array}{l}\text { Polymeric binder } \\
\text { (solid content) }\end{array}$ & 25 & 25 & 25 & 25 \\
\hline NFC1 (solid content) & 0.25 & 0.25 & 0.25 & 0.25 \\
\hline Defoamer & $0.5^{\mathrm{a}}$ & $0.5^{\mathrm{a}}$ & $0.5^{\mathrm{b}}$ & $0.5^{\mathrm{b}}$ \\
\hline Wetting agent $^{\mathrm{c}}$ & 0.2 & 0.2 & 0.2 & 0.2 \\
\hline Film forming agent ${ }^{\mathrm{d}}$ & - & - & - & 2.85 \\
\hline Deionized water & 74.05 & 74.05 & 74.05 & 71.2 \\
\hline Sum & 100 & 100 & 100 & 100 \\
\hline
\end{tabular}

Table 1 Types and suppliers of used acrylate polymer emulsions (binders)

\begin{tabular}{lllll}
\hline Acronym & Commercial name & Supplier & Polymer and stabilization & Solid content [\%] \\
\hline Acr1 & Alberdingk & Alberdingk Boley GmbH, & Acrylic acid/methacrylic acid \\
& AC 2739 & Germany & Anionic, acrylic emulsion & $44-46$ \\
Acr2 & Acronal DS 6288 & BASF SE, Germany & $\begin{array}{l}\text { Acrylic acid/methacrylic acid styrene } \\
\text { co-polymer, anionic surfactants }\end{array}$ & $49-51$ \\
Acr3 & Mowilith & Celanese, USA & Anionic, acrylic co-polymer emulsion & 44 \\
& LDM 7416 & & & \\
\hline
\end{tabular}




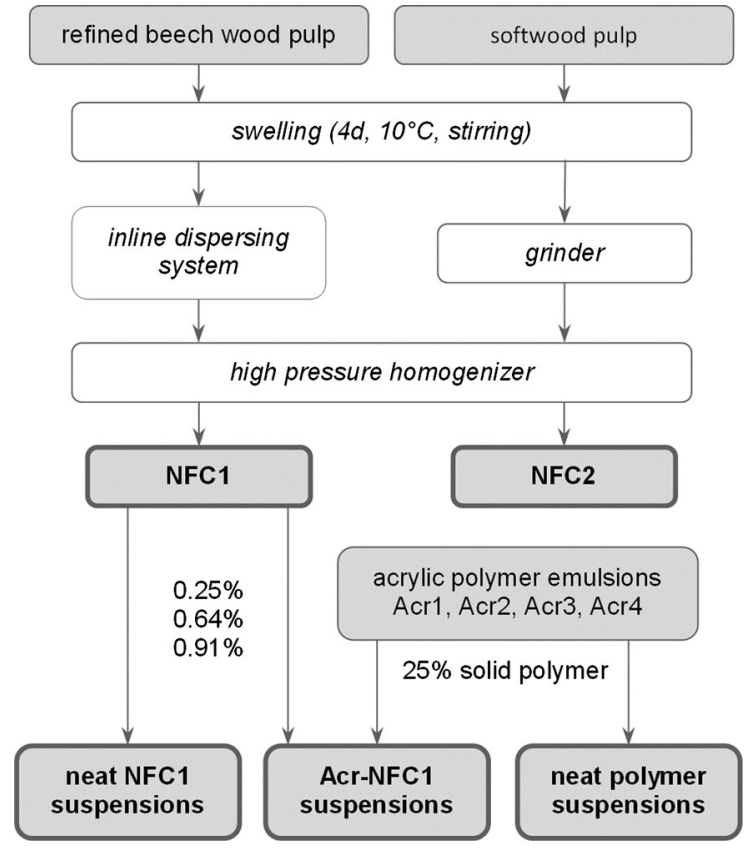

Fig. 1 Schematic overview of NFC disintegration processes and sample preparation for rheology measurements; intermediate sampling for quality and fibrillations process control is not included

Masuko Sangyo Co. Ltd., Japan). This was necessary because the pulp fibres were too long and therefore clogged the inline dispersing system used for the pretreatment of the other raw material. A softwood pulp suspension of $2 \%(\mathrm{w} / \mathrm{w})$ in deionized water was prepared and premixed using a blender. After swelling it for 4 days at $10{ }^{\circ} \mathrm{C}$ under constant stirring, the suspension was passed through the grinder 10 times. After seven passes, the suspension was diluted with water to $1.8 \%(\mathrm{w} / \mathrm{w})$ to decrease viscosity. In the second step, the suspension was transferred to the high pressure homogenizer, diluted to $1.5 \%(\mathrm{w} / \mathrm{w})$ and processed as described before for the NFC1. The resulting NFC material is named NFC2.

Both NFC suspensions were concentrated by centrifugation for storage in the fridge.

\section{Preparation of acrylate-NFC1 suspensions}

Acrylate-NFC1 suspensions were prepared according to a standard coating formulation based on the suppliers' recommendations (Table 2). For all suspensions, a constant acrylic polymer solid content of $25 \%(\mathrm{w} / \mathrm{w})$ was used. NFC1 concentration was varied from 0.25 over 0.64 to $0.91 \%(\mathrm{w} / \mathrm{w})$ in the suspension to achieve concentrations of $1,2.5$ and $3.5 \%$ of dry NFC1 referred to the solid polymer. These are typical concentrations for coating additives. Some essential additives for processing were added to the suspensions, such as a defoamer, to minimize foaming during processing, a wetting agent to have a better substrate wetting, and a film forming agent. Table 2 shows the standard formulation of acrylate-NFC1 suspensions with $0.25 \%$ (w/w) NFC content and the different additives used depending on the acrylate raw materials.

For suspension preparation, the acrylate polymer emulsions were first diluted with the calculated amount of water and the additives were added while stirring with a dissolver stirrer. The NFC1 was added in form of the concentrated suspension obtained as described above. The suspensions were stirred for $30 \mathrm{~min}$ and stored at $20^{\circ} \mathrm{C}$. As depicted in the schematic overview in Fig. 1, neat NFC1 suspensions at the same NFC concentrations and reference polymer suspensions containing the polymer and the additives without NFC were prepared as well.

\section{Characterization}

\section{Degree of polymerization (DP)}

The limiting viscosity number $[\eta]$ of the used cellulose raw materials and the NFC thereof were determined according to ISO 5351 (ISO 2004). Beech wood pulp, softwood pulp, NFC1 and NFC2 were first dried via freeze drying and afterwards in the oven at $50{ }^{\circ} \mathrm{C}$ for at least $24 \mathrm{~h}$. Depending on the assumed DP, a defined amount of material was dissolved in cupri-ethylenediamine solution. The running time of these solutions through a capillary tube viscometer was determined and the limiting viscosity number $[\eta]$ was calculated with the help of the Schulz-Blaschke formula (ISO 2004). The average DP of the cellulose and NFC samples was calculated from $[\eta]$ using the StaudingerMark-Houwink equation (Gruber and Gruber 1981).

\section{Scanning electron microscopy (SEM)}

Cellulose raw materials and NFC suspensions were diluted with deionized water to $0.1 \%(\mathrm{w} / \mathrm{w})$ and mixed using the homogenizer. A drop of the diluted suspensions was placed onto a mica plate laminated 
specimen holder. The samples were dried in vacuum and sputtered directly with a platinum layer of $8 \mathrm{~nm}$ (BAL-TEC MED 020 Modular High Vacuum Coating Systems, BAL-TEC AG, Lichtenstein). SEM images were recorded with a FEI Nova NanoSEM 230 instrument (FEI, USA) with an accelerating voltage of $5 \mathrm{kV}$ and a working distance of $5 \mathrm{~mm}$.

\section{Rheology of neat NFC suspensions}

Samples of NFC2 suspensions were taken for process monitoring during the fibrillation process after each pass through the grinder and after 2, 5, 8 and 10 passes through the interaction chambers of the high pressure homogenizer. NFC1 and NFC2 suspensions of 0.5, 0.75 and $1 \%(\mathrm{w} / \mathrm{w})$ were then further prepared for quality assessment after the fibrillation process by mixing them at $11,000 \mathrm{rpm}$ using a homogenizer (Ultra-Turrax T25 digital, IKA Werke, Germany) for $3 \mathrm{~min}$ to achieve homogeneous dispersion. The resulting samples were degassed under vacuum to remove trapped air bubbles.

The rheological measurements were performed with a rotational rheometer with concentric cylinder geometry (Rheolab QC, CC39 geometry, $1.64 \mathrm{~mm}$ gap size, Anton Paar, Austria). The measurements were conducted at $25{ }^{\circ} \mathrm{C}$ in controlled shear rate mode by varying the shear rate from $=0.1$ up to 1,000 and back to 0.1 1/s. A duplicate of each measurement was performed.

\section{Rheology of acrylate-NFC suspensions}

Acrylate-NFC suspensions were used as described above without further preparation. Measurements were done with a rotational rheometer with a higher measurable viscosity range compared to the rheometer used before (Physika MCR300, concentric cylinder CC27 geometry, $1.13 \mathrm{~mm}$ gap size, Anton Paar, Austria). The controlled shear rate experiments were done as described above. Each measurement was performed in duplicates.

\section{Storage stability of acrylate-NFC suspensions}

The storage stability of selected acrylate-NFC suspensions was evaluated by monitoring the viscosity during an accelerated storage experiment. Because of the lack of a standard method, an own method was set up according to several suggestions found in literature (Koleske 2012). Acrylate-NFC suspensions with Acr2 and Acr3 and the corresponding neat NFC1 suspensions were tested. Sealed bottles with the suspensions were stored in a laboratory oven at $40{ }^{\circ} \mathrm{C}$ for 4 weeks. Rheological measurements as described before were done at the beginning and after each week during the accelerated storage. The suspensions were stirred slightly before measurement.

\section{Results and discussion}

Fibrillation of cellulose raw materials

Figure 2 shows SEM micrographs of the raw materials, intermediate products of NFC2 and the final NFC products. The beech wood pulp (Fig. 2a) was delivered already refined and therefore appeared as fibrillated material with fibre diameters in $\mathrm{nm}$ and $\mu \mathrm{m}$ range. After high pressure homogenization, the final NFC1 (Fig. 2b) was much finer than before fibrillation. In contrast, the softwood pulp (Fig. 2c) consisted solely of fibres with diameters in the $\mu \mathrm{m}$ range. It was therefore necessary to use a grinder in the first disintegration step to avoid clogging of the interaction chambers in the high pressure homogenizer. Figures $2 \mathrm{~d}$, e represent the softwood pulp after 7 and 10 grinding passes, where the fibres were strongly fibrillated compared to the initial fibre size. The fibrillation grade increased with the number of passes, but still occasional bigger fibres were noticed. During processing with the high pressure homogenizer, the fibres got finer (images not shown) and resulted in NFC2 (Fig. 2f), which showed the finest fibres and highest homogeneity among all disintegrated materials after the complete fibrillation process. Both NFC types built up the typical NFC network structure reported many times in literature (Klemm et al. 2011).

In addition to the visual evaluation, other methods were used to monitor the fibrillation quality. A common way to analyse NFC and their untreated raw materials is the determination of the degree of polymerization (DP). The DP of native celluloses is usually between 20,000 and 40,000 , depending on the cellulose source. This initial DP is usually reduced by purification procedures to 2,500 and by regeneration processes to 200-400 (Nevell and Zeronian 1985). As already described in the very early papers on NFC, the 

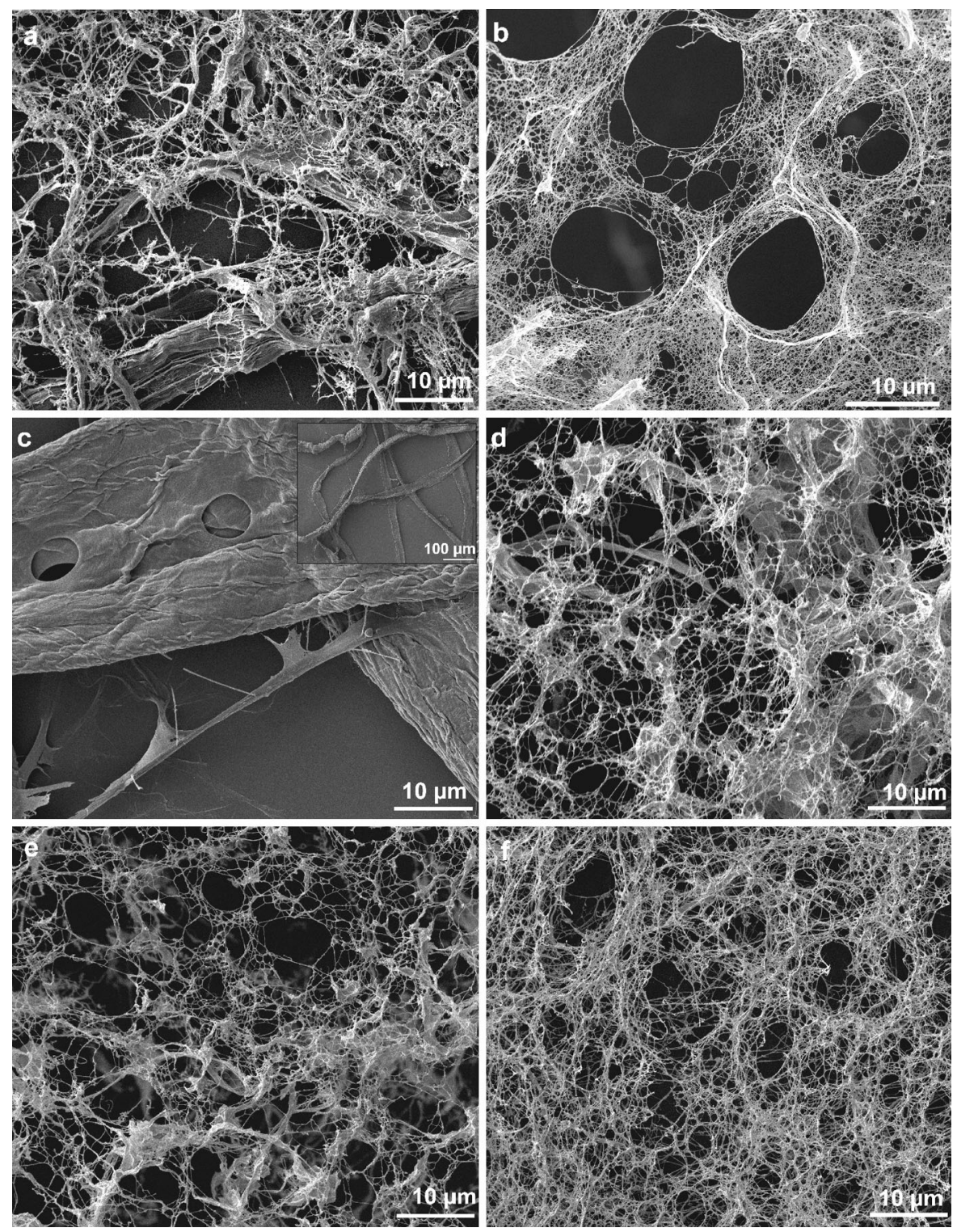

Fig. 2 SEM micrographs of the cellulose raw materials and of the produced NFC: a refined beech wood pulp, b NFC1 after the mechanical disintegration process with inline dispersing system and high pressure homogenizer, softwood pulp before $\mathbf{c}$ and

after 7 (d) and 10 (e) passes through the grinder, f NFC2 after the complete disintegration process with grinder and high pressure homogenizer

DP usually decreases during the fibrillation process of cellulose by high pressure homogenization as well as by grinding (Herrick et al. 1983; Zimmermann et al. 2010). The determined DPs of the used cellulose pulps and NFCs presented in Table 3 are in good agreement with the literature. Both raw materials had their DP in a comparable range 1,440 for the beech wood pulp and 1,541 for the softwood pulp, respectively. This might be surprising, as the fibres looked far different, but

indeed it should be considered, that the DP is not directly correlated to the fibre length and diameter (Iwamoto et al. 2007). After processing, both NFC had decreased DP values compared to the starting materials, between 981 and 1,108 for NFC1 and between 1,059 and 1,113 for NFC2. For the softwood pulp, a stepwise decrease of the DP of the starting cellulose $(1,541)$, to the grinded cellulose $(1,292)$ and the final NFC2 (1,059 and 1,113) was apparent. 
Table 3 Degree of polymerization (DP) of cellulose raw materials and produced NFC

\begin{tabular}{lll}
\hline & DP & \\
\cline { 2 - 3 } & NFC1 & NFC2 \\
\hline Raw material & 1,440 & 1,541 \\
After grinder & - & 1,292 \\
NFC (1st batch) & 1,108 & 1,059 \\
NFC (2nd batch) & 981 & 1,113 \\
\hline
\end{tabular}

Since the determination of the DP can be time consuming and laborious, rheology was chosen as additional method for process monitoring and quality assessment.

\section{Rheology of NFC suspensions}

\section{Flow curves of NFC suspensions}

The general flow behaviour of the used NFC is discussed briefly, before going into details about using rheology measurements for process monitoring and quality assessment. Rotational measurements with controlled shear rate were conducted and a typical flow curve is given in Fig. 3 for the suspension of $\mathrm{NFC} 1$ at $1 \%$ concentration. Rheology measurements of NFC2 resulted in similar flow curves. Measurements were done with both, increasing and decreasing shear rates. The flow curve of the NFC1 suspension shown in Fig. 3 exhibits a shear thinning behaviour, as already known from the very early works on NFC (Herrick et al. 1983). The flow behaviour in the upper shear region (above $10 \mathrm{l} / \mathrm{s}$ ) does not depend on the flow history and direction of measurement. In the lower shear region, differences appear. The viscosity and especially the shear stress of the first measurement at increasing shear rates are augmented compared to the second (decreasing shear rate) and third (increasing shear rate) measurement. In addition, a small hysteresis is visible. A more distinct hysteresis was already described by Iotti et al. (2011). They described three network structures, a no-shear structure with a yield stress, a high shear structure with pure shear thinning behaviour above the hysteresis and a lowshear structure. This model fits well to the flow behaviour presented in Fig. 3. With increasing shear rate, the inner structure of the NFC suspension is broken down slowly, until the yield stress is reached.

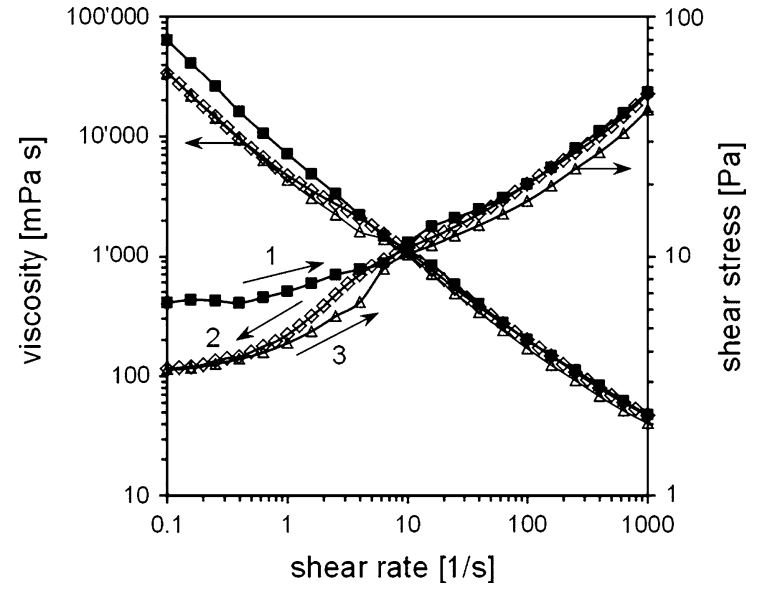

Fig. 3 Flow curves of NFC1 suspension at $1 \%$ NFC content; (filled square) 1st measurement step after filling the sample into the cup from low to high shear rates, (open diamond) 2nd step from high to low shear rates, (open triangle) 3rd step from low to high shear rates

This is especially visible for the shear stress in measurement 1 of Fig. 3. The hysteresis represents the transition between the no- or low-shear region and the high shear region. A shear induced structure is formed. These results are in line with earlier, detailed investigations (Karppinen et al. 2012; Saarikoski et al. 2012; Björkman 2006). Karppinen et al. (2012) and Saarikoski et al. (2012) investigated the same shear regions by recording a movie of NFC suspensions while doing rheological measurements. Thereby, they could visualize the structural changes in the NFC microstructure. Björkman (2006) described the flow behaviour of concentrated fibre suspensions in general and set up the module suspension theory: he reduced suspension flocs to rectangular model flocs and stated that increased shear stress leads to a squeezing out of liquid from the flocs. In consequence, the shape of the model flocs change and flocs are separated into smaller module flocs. This structural change causes the flow behaviour observed in our experiments.

Additionally to the changing floc structure in the NFC suspension, the effect of wall slip or wall depletion on the flow chart should be considered. Wall slip is known to be present in two-phase systems, such as high molecular weight polymer solutions, particulate or flocculated suspensions, such as NFC suspensions, or even emulsions with large droplet sizes (Barnes 1995). The continuous phase enriches at the geometry boundary and forms a very thin layer 
depleted of the dispersed phase. During shear, the real shear rate at the geometry boundary is higher than in the bulk of the suspension, which results in a lower measured viscosity than the real viscosity of the suspension (Saarikoski et al. 2012). This effect is emphasized more at decreasing measuring gap sizes in relation to the particle size and its impact on the measuring results is the highest at low flow rates. For this reason, this effect may also result in false thixotropy and false yield stress (Barnes 1995). Wall slip might be minimized or prevented by using a roughened measuring geometry, which was not used in our experiments. The measuring gap size of $1.64 \mathrm{~mm}$ was comparably large and according to Saarikoski et al. (2012) would therefore result in decreased floc size during shear. At least at higher shear rates, the adulterant effect of wall slip should be minimized due to the reduced floc size. Saarinen et al. (2014) additionally could visualize that when measuring above the yield stress, a slipping layer was present but the bulk of the suspension was also shared throughout the whole gap. For this reason, the comparison of different suspensions in the presented experiments was mainly done at high shear rates. Moreover, the viscosity measurement from high to low shear rate, which was independent from the sample history, was chosen for further comparisons over the whole shear rate range.

\section{Fibrillation monitoring}

The fibrillation progress of the softwood pulp was monitored in detail with the help of viscosity measurements and results are presented in Figs. 4 and 5. Figure 4 displays the flow curves of the softwood pulp suspensions (NFC2) during the grinding process. Figure 5 contains the viscosity values at a fixed shear rate of $100 \mathrm{l} / \mathrm{s}$ during the whole fibrillation process. Measurements of the starting softwood pulp and of material which passed less than 7 times through the grinder were not possible to record. Based on an insufficient fibrillation, the fibres were still too long and resulted in inhomogeneous suspensions. The flow curves of these suspensions were very irregular and phase separation was observed.

Figures 4 and 5 show that each pass through the grinder and the high shear homogenizer led to a viscosity increase, as already described earlier by other groups (Saito et al. 2006; Lasseuguette et al.

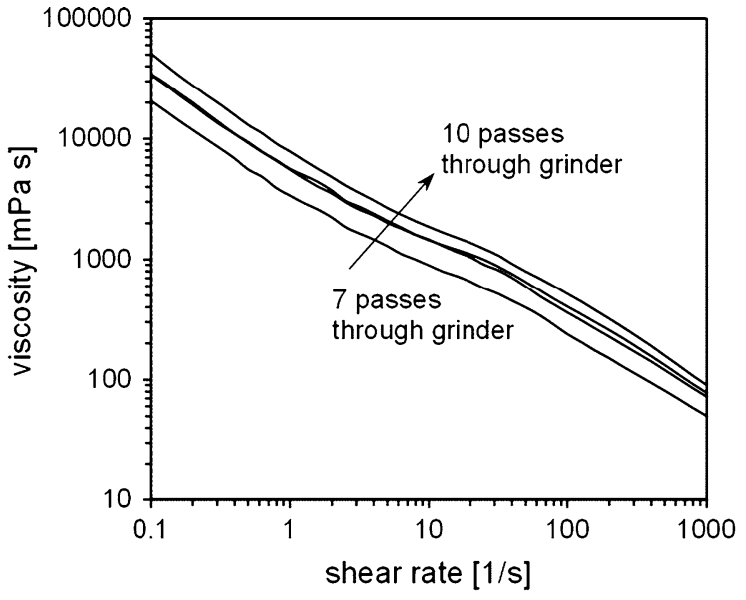

Fig. 4 Flow curves of softwood pulp suspensions after 7, 8, 9 and 10 passes through the grinder at $1.8 \%(\mathrm{w} / \mathrm{w})$ concentration

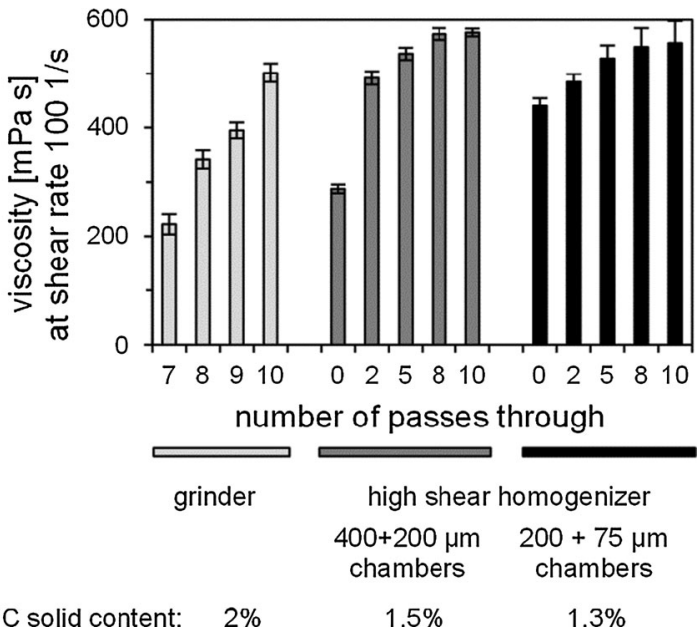

Fig. 5 Viscosity values at shear rate of 100 1/s of softwood pulp suspensions (NFC2) at different stages of the fibrillation process; the error bars correspond to the standard deviation of three replicates

2008; Saarikoski et al. 2012). It was apparent as well, especially for the fibrillation step with the high shear homogenizer that the viscosity increase levelled off after a certain number of passes. For both interaction chamber combinations, the viscosity changed only little after 5-8 passes. For example, while fibrillating within the 75 and $200 \mu \mathrm{m}$ interaction chambers of the high shear homogenizer, the viscosity first increased distinctly from 440 to 485 ( 2 passes), 528 (5 passes) and $550 \mathrm{mPa}$ s (8 passes) and finally only increased little to $557 \mathrm{mPa}$ s after 10 passes. Therefore, process 
optimization was possible and the number of passes through the high shear homogenizer could be reduced for the next fibrillation batches.

In Fig. 5 the increase in viscosity within one fibrillation step seems to be followed by a strong decrease while changing, e.g., from the grinding to the high shear homogenization process. This was due to varying cellulose concentrations during the different process steps and due to different sample histories prior to measurement.

Thus, NFC1 and NFC2 suspensions with defined cellulose solid contents and a reproducible preparation method were prepared at two different stages of fibrillation. The corresponding results are displayed in Fig. 6. The refined beech pulp, raw material of NFC1, exhibited the lowest viscosities at all three tested concentrations. The suspension with $1 \%$ refined beech pulp content had a viscosity of $35 \mathrm{mPa} \mathrm{s}$ at $100 \mathrm{l} / \mathrm{s}$. After the whole fibrillation process, the resulting NFC1 had eightfold higher viscosity values, 280 and $268 \mathrm{mPa}$ s for a first and second batch of $\mathrm{NFC1}$, respectively. Additionally taking into account the values of the suspensions at 0.5 and $0.75 \%$ NFC

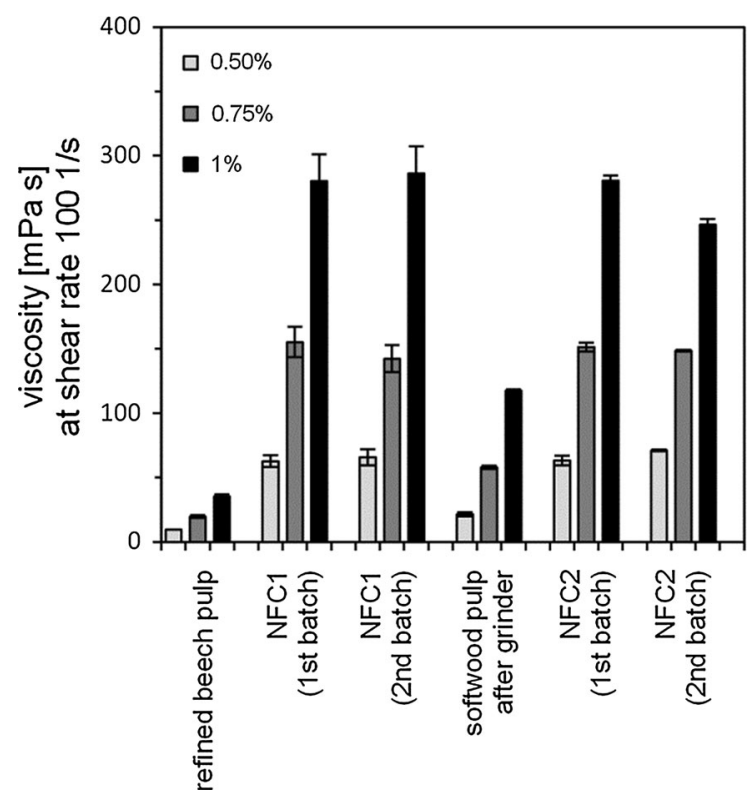

Fig. 6 Viscosity values at shear rate of $100 \mathrm{l} / \mathrm{s}$ for NFC1 and NFC2 suspensions, suspensions of the starting refined beech pulp and the softwood pulp after grinding at defined concentrations of $0.5,0.75$ and $1 \% \mathrm{NFC}(\mathrm{w} / \mathrm{w})$; the error bars correspond to the standard deviation of three replicates content, it is obvious that the viscosity measurements and thus the fibrillation were reproducible. Moreover, the viscosities of the NFC1 suspensions were also comparable to the corresponding results of NFC2. These values were in the same range, being 281 and 247 for the first and second batch at $1 \%$ NFC2 content. It is remarkable, that the quality of the two NFC2 batches did not change significantly, although the number of fibrillation passes through the high pressure homogenizer was reduced to 8 instead of 10 as described above. Figure 6 also contains the viscosity values of the softwood pulp measured after the sole grinding process without high pressure homogenizer treatment. At $1 \%$ solid content, the viscosity of this intermediate product was only $118 \mathrm{mPa}$ s and therefore lower than the values of the final NFC2.

These results show that easy to handle viscosity measurements with a rotational rheometer are a convenient and also fast method to monitor and optimize the fibrillation process and to conduct quality control. These results were supported by SEM images of the same samples, were the changes in fibre dimensions could be visualized. Thus, the optimum number of passes through a disintegration device can be determined, which also helps, e.g., to save energy costs.

\section{Preparation of acrylate-NFC1 suspensions}

Only NFC1 was used for the preparation of the acrylate-NFC suspensions due to availability. Four different commercial acrylic polymer emulsions were selected, to cover a broad range of polymers with different properties. All of these polymer emulsions are typical binders for exterior wood coating applications. In general, waterborne emulsified polymers were used due to environmental reasons.

Formulation recommendations for fully functioning wood coatings, namely transparent stains, were provided by the suppliers of the polymer emulsions. For our own standard formulation, the components were reduced to a necessary minimum and the composition is summarized in Table 2. Suspensions with higher NFC concentrations than $0.91 \%$ were hardly processible without any additional degassing. The viscosity of suspensions with higher NFC content became too high, so that air bubbles were trapped in the suspensions, which would have led to incorrect viscosity measurements. 
Rheology of acrylate-NFC1 suspensions

\section{Neat acrylate polymer emulsions}

Figure 7 contains the flow curves of the acrylate emulsions at high solid content of $44 \%$ and lower solid content of $25 \%$, which corresponds to the polymer content in the NFC-polymer suspensions and which will be discussed later. At $44 \%$, Acr1, Acr2 and Acr3 possessed shear thinning behaviour at higher shear rates and the Acr4 showed Newtonian flow behaviour over the whole measuring range. The values and flow characteristics differed from each other most probably due to different surface properties and modes of stabilization, which were not known in detail. At a reduced solid content of $25 \%$, flow curves of the different diluted emulsions were similar to each other, although these acrylates had different flow behaviours at the initially higher solid contents (Fig. 7). The viscosity was decreased compared to the undiluted emulsions and exhibited Newtonian flow behaviour. At $25 \%$ solid content the polymer emulsions were diluted so much that interactions between the emulsion particles, which would promote non-Newtonian behaviour, were prevented and therefore Newtonian flow curves were measured. Interestingly, the viscosity was more or less the same for all acrylates and only a little higher than the viscosity of pure water at $25^{\circ} \mathrm{C}$ (0.89 $\mathrm{mPa} \mathrm{s})$. Only the viscosity of Acr1 was slightly higher.

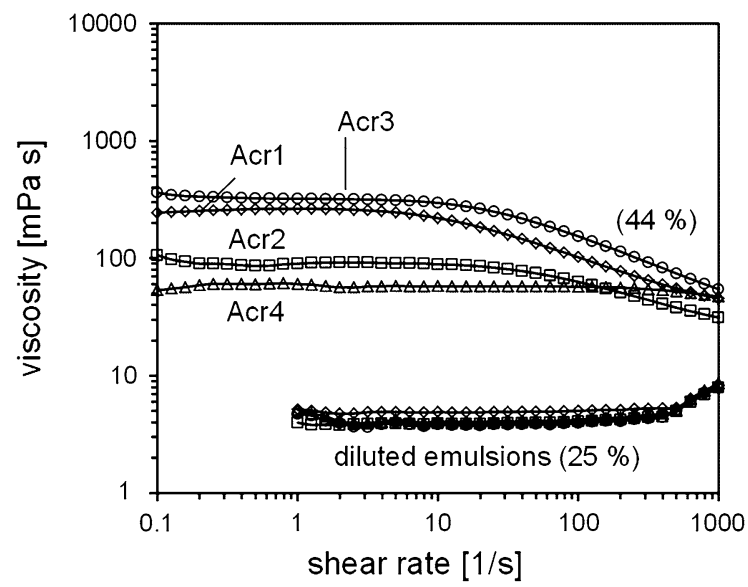

Fig. 7 Flow curves of the four neat acrylate polymer emulsions at $44 \%$ solid contents and diluted emulsions at $25 \%$ solid content; symbols of diluted emulsions correspond to the ones of neat emulsions
The increase of viscosity in the upper end of the measuring interval is assumed to be due to turbulences, which are common for low viscosity liquids at high shear rates (Mezger 2011).

\section{Acrylate-NFC1 suspensions}

The addition of NFC1 to the diluted acrylate suspensions led to an increase in viscosity and changed the general flow behaviour. Figure 8 shows exemplarily the flow curves of all Acr2-NFC1 suspensions and of neat NCF1 suspensions at the same concentration. It is obvious, that the general flow behaviour changed from Newtonian flow (diluted acrylate emulsions) to shear thinning flow (acrylate-NFC1 suspensions). Furthermore, the viscosity increased with increasing NFC1 concentration, e.g. from $3.9(0 \% \mathrm{NFC} 1)$ to 8.0 (0.25\% NFC1), 31.5 (0.64\% NFC1) and $76.4 \mathrm{mPa} \mathrm{s}$ $(0.91 \% \mathrm{NFC} 1)$ at the fixed shear rate of $100 \mathrm{l} / \mathrm{s}$. At this point, the viscosity increased by a factor of nearly 20. The correlation between NFC1 concentration and viscosity at $100 \mathrm{l} / \mathrm{s}$ is further depicted in Fig. 9. A linear increase of the viscosity on the logarithmic scale after NFC1 addition is visible. Consequently, the viscosity of acrylate-NFC1 suspensions is exactly tuneable in the considered shear range by NFC1 addition.

Besides the flow curves of the acrylate-NFC1 suspensions, Figs. 8 and 9 also contain the values of

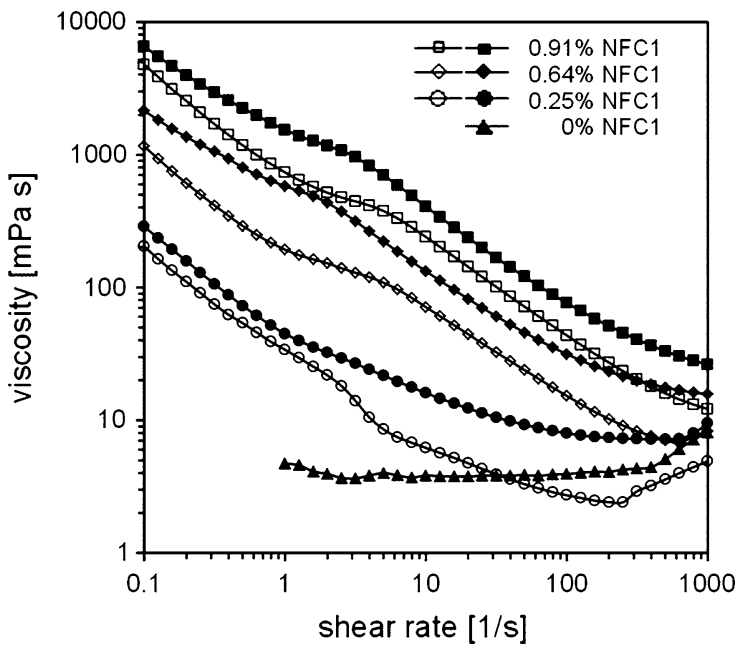

Fig. 8 Flow curves of Acr2-NFC1 suspensions (filled symbols) at different NFC1 concentrations and corresponding neat NFC1 suspensions (empty symbols) 


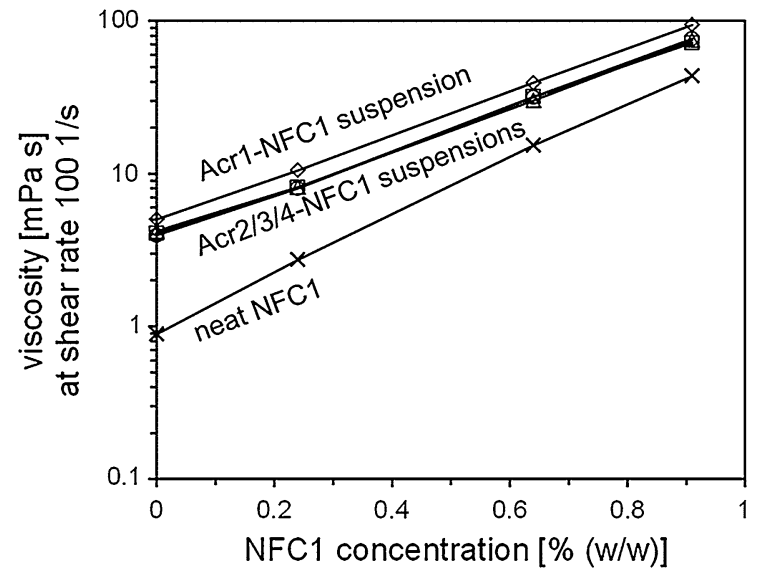

Fig. 9 Viscosity values of acrylate-NFC1 suspensions and neat NFC1 suspensions at shear rate of $100 \mathrm{l} / \mathrm{s}$ depending on NFC concentration

neat NFC1 suspensions at the corresponding concentrations. Since sample preparation has a big impact on the viscosity, we ensured comparable viscosity measurements by preparing neat NFC1 suspensions and acrylate-NFC suspensions the same way. The general flow characteristics of both suspensions were comparable. They were shear thinning and in both cases the viscosity increased with higher NFC1 content. However, the viscosity values of the acrylate-NFC1 suspensions were always higher than those of the corresponding neat NFC1 suspensions. We suppose that the higher solid content in the suspension and interactions between NFC1 and acrylate particles were responsible for these results. Nevertheless, the influence of the acrylic polymers on the flowing properties of the acrylate-NFC1 suspensions was very low and the characteristics of NFC1 were predominant. This result was underlined by the fact that curves and viscosity values of the acrylate-NFC1 suspensions were nearly independent from the type of acrylate and its initial flow behaviour (compare Fig. 7). Again, only Acr1 exhibited higher values, which was neither explainable nor further investigated.

The viscosity change after addition of NFC1 to acrylate emulsions is comparable to conventional thickeners and rheology modifiers. Nowadays, such thickeners are mainly used in paint and coating formulations to adjust coating consistency in the so called mid-shear region (10-1,000 1/s), the main shear region for coating processing (Koleske 2012). The increased viscosity due to NFC1 addition in the low shear region (less than $10 \mathrm{l} / \mathrm{s}$ ), which describes the coating at rest, seems to be favourable. High viscosity in this region prevents for instance pigment settling during storage or sagging of the coating on vertical surfaces (Molenaar 1997). The impact of NFC1 addition to the high shear region (more than 1,000 1/s), which describes the coating properties during application, e.g., brushing or spraying, was not further investigated. Anyway, the desired flowing properties in the three regions are always related to the application and vary depending on the raw materials of a coating composition. It should also be considered, that we used neat polymeric binder materials with only few additives to investigate the sole impact of NFC addition. Ready-to-use wood coatings also contain other components such as $\mathrm{TiO}_{2}$ as a white pigment or silicates for improving the mar-resistance (Wicks et al. 2006). These additives, which were not used in this study, will affect the coating rheology themselves and might even affect it due to interaction with the NFC.

Accelerated storage stability of acrylate-NFC1 suspensions

The stability of acrylate-NFC1 suspensions was evaluated by monitoring the viscosity during accelerated storage for the period of 4 weeks at $40{ }^{\circ} \mathrm{C}$ in a laboratory oven. Results of these viscosity measurements are presented in Figs. 10 and 11. Figure 10 shows the viscosity change during the accelerated storage of the Acr2-NFC1 suspension with $0.91 \%$ NFC1 concentration. The general flow behaviour was not affected during storage, but the viscosity

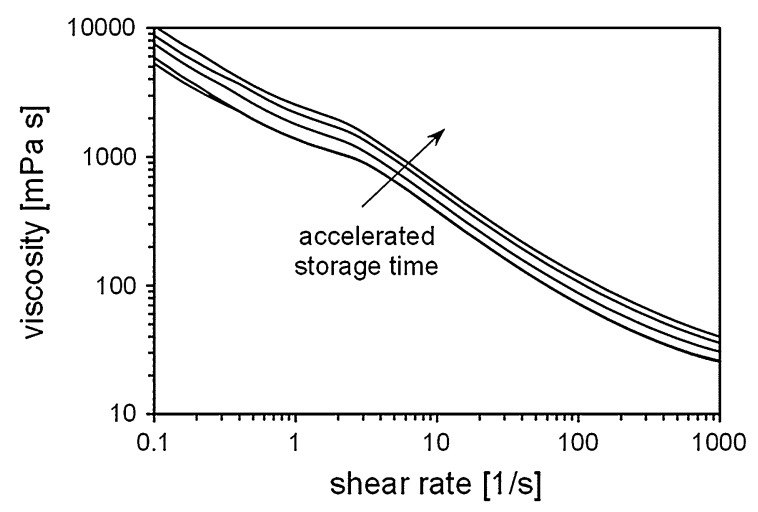

Fig. 10 Flow curves of Acr2-NFC1 suspension with $0.91 \%$ $\mathrm{NFC1}$ during accelerated storage for 4 weeks at $40{ }^{\circ} \mathrm{C}$ 


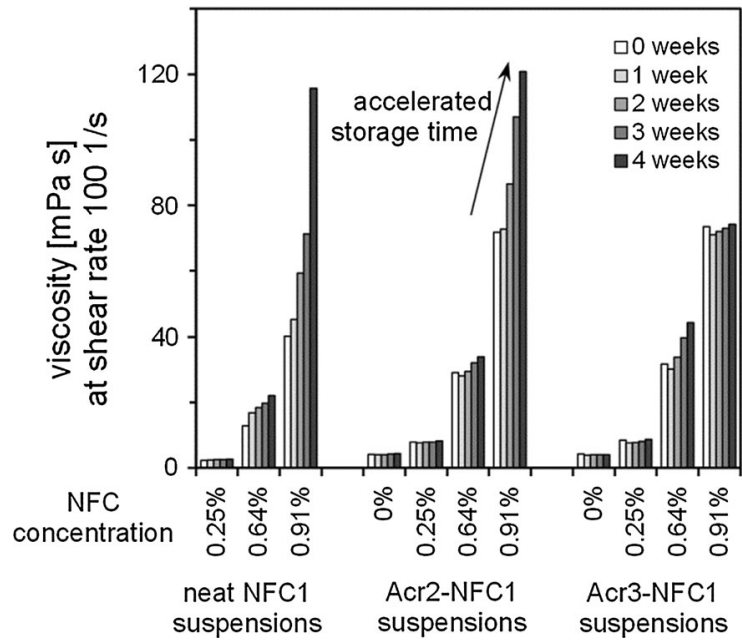

Fig. 11 Development of viscosity values during accelerated storage of selected acrylate-NFC1 suspensions with Acr2 and Acr3 and as reference neat NFC1 suspension at shear rate of $100 \mathrm{l} / \mathrm{s}$

increased. The results of all tested suspensions are summarized in Fig. 11. The viscosity of suspensions with NFC1 content of $0.25 \%$ or without NFC1 did not change significantly. Suspensions with higher NFC1 contents generally exhibited increased viscosities after storage as already described for the Acr2-NFC1 suspension with $0.91 \%$ NFC1. Only the viscosity of the Acr3-NFC1 suspension with $0.91 \%$ NFC1 content kept constant after storage. This deviating result was not further investigated.

No appropriate literature was found to explain the viscosity increase of NFC-suspensions during storage at increased temperatures. Several, speculative aspects might be considered to explain these observations. On the one hand, the interfibrillar interaction might be increased due to more entanglements and hydrogenbonds between single fibrils. Such increased interactions would increase the resistance to flow and therefore the viscosity of a suspension.

On the other hand, swelling of the NFC might be a reason. Swelling is very well reported for native dried and never-dried cellulose, dry NFC films and composites containing NFC, but not for suspended NFC (Eyholzer et al. 2011; Ahola et al. 2008; Spinu et al. 2011). In general, water diffuses into the amorphous part of cellulose and causes swelling of the entire material (Aulin et al. 2009). Swelling of NFC fibrils followed by increased NFC floc size might be explained with the time and temperature dependence of diffusion and with size effects. Fick's second law of diffusion includes the time dependence of diffusion and according to the Einstein relation, the diffusion coefficient depends on the temperature (Atkins and De Paula 2006). The diffusion coefficient increases with increasing temperature, which could explain additional swelling of NFC due to accelerated diffusion at the higher storage temperature $\left(40{ }^{\circ} \mathrm{C}\right)$. In addition, the diffusion of water is enhanced by the increased fibre surface compared to the fibres before fibrillation. Such phenomena were already described for wood pulp fibres in $8 \% \mathrm{NaOH}$ solutions at low temperatures (Spinu et al. 2011). In that study, highly fibrillated fibres swelled much faster compared to larger fibres and at lower $\mathrm{NaOH}$ concentrations, only the fibrillated fibres swelled.

Both discussed aspects, interfibrillar interaction and swelling, need to be proved by further investigations, as they are only speculative.

The main conclusion of this accelerated storage experiment with regard to the coating application is, that although the viscosity slightly increased, the general flow behaviour did not change. Hence, from a practical point of view, a potential paint or coating containing NFC would need to be diluted accordingly after long time storage. Afterwards, the same flowing characteristics would be obtained again.

\section{Conclusion}

Nanofibrillated cellulose (NFC) was disintegrated from two different cellulose raw materials by using adapted fibrillation processes depending on the initial fibre size. Rheological measurements were found to be a convenient and also fast method for fibrillation process monitoring (quality control) and subsequent optimization.

In a second step, the viscosity of water-borne acrylate-NFC suspensions was investigated with regard to a potential use of NFC in coating compositions. The flow characteristics of the NFC were dominating the acrylate-NFC suspensions and the type of polymer was of minor importance for the rheological behaviour of the tested suspensions. The viscosity increased exponentially due to NFC addition. Consequently, the viscosity of acrylate-NFC suspensions is precisely adjustable and predictable in 
the considered shear range by NFC addition. The general flow behaviour of the acrylate-NFC suspensions remained the same during accelerated storage at elevated temperatures. Possible explanations of the increasing viscosity of NFC and acrylate-NFC suspensions under the influence of temperature and time might be increased interactions between single fibrils within the network and/or swelling of the NFC due to increased water diffusion and increased fibre surface. Both impacts might increase the resistance to flow and therefore the suspension viscosity.

The study shows that rheology is an important issue that has to be taken into account when applying NFC as additive in water based coating systems and that NFC is suitable as component for coating applications.

Acknowledgments This work was financially supported by the Swiss National Science Foundation (SNF) within the National Research Programme 66 (NRP 66) "Resource Wood" (Project-Nr. 406640-136558). We kindly thank Esther Strub for performing the DP measurements and SEM characterization and Paola Orsolini and Sebastien Josset for the grinding of NFC2. We are grateful for valuable comments and discussions on the manuscript with I. Burgert. We also thank the companies mentioned in the experimental part for the provision of the coating and cellulose raw materials.

\section{References}

Agoda-Tandjawa G, Durand S, Berot S, Blassel C, Gaillard C, Garnier C, Doublier JL (2010) Rheological characterization of microfibrillated cellulose suspensions after freezing. Carbohydr Polym 80(3):677-686. doi:10.1016/j. carbpol.2009.11.045

Ahola S, Salmi J, Johansson LS, Laine J, Österberg M (2008) Model films from native cellulose nanofibrils. Preparation, swelling, and surface interactions. Biomacromolecules 9(4):1273-1282. doi:10.1021/bm701317k

Atkins P, De Paula J (2006) Physical chemistry, 8th edn. Oxford University Press, Oxford

Aulin C, Ström G (2013) Multilayered alkyd resin/nanocellulose coatings for use in renewable packaging solutions with a high level of moisture resistance. Ind Eng Chem Res 52(7):2582-2589. doi:10.1021/ie301785a

Aulin C, Ahola S, Josefsson P, Nishino T, Hirose Y, Österberg M, Wågberg L (2009) Nanoscale cellulose films with different crystallinities and mesostructures-their surface properties and interaction with water. Langmuir 25(13):7675-7685. doi:10.1021/la900323n

Barnes HA (1995) A review of the slip (wall depletion) of polymer solutions, emulsions and particle suspensions in viscometers: its cause, character, and cure. J Non Newton Fluid Mech 56:221-251

Björkman U (2006) The metarheology of crowded fibre suspensions. Ann Trans Nord Rheol Soc 14:69-78
Boluk Y, Zhao L, Incani V (2012) Dispersions of nanocrystalline cellulose in aqueous polymer solutions: structure formation of colloidal rods. Langmuir 28(14):6114-6123. doi:10.1021/la2035449

Bousfield DW, Richmond F, Bilodeau M (2013) The properties of paper coating layers that contain cellulose nanofibrils. In: TAPPI international conference on nanotechnology for renewable materials, Stockholm, Sweden

Bulian F, Graystone JA (2009) Properties of wood coatingstesting and characterisation. In: Bulian F, Graystone JA (eds) Wood coatings. Elsevier, Amsterdam, pp 155-194. doi:10.1016/B978-0-444-52840-7.00006-0

Cavaille JY, Chanzy H, Favier V, Ernst B (2000) Cellulose Microfibril-reinforced polymers and their applications. France Patent USA 6103790

Dufresne A (2012) Nanocellulose, from nature to high performance tailored materials. Walter de Gruyter, Berlin/Boston

Eyholzer C, Borges de Couraça A, Duc F, Bourban PE, Tingaut P, Zimmermann T, Månson JAE, Oksman K (2011) Biocomposite hydrogels with carboxymethylated, nanofibrillated cellulose powder for replacement of the nucleus pulposus. Biomacromolecules 12(5):1419-1427. doi:10. 1021/bm101131b

Favier V, Canova GR, Cavaille JY, Chanzy H, Dufresne A, Gauthier C (1995) Nanocomposite materials from latex and cellulose whiskers. Poly Adv Technol 6(5):351-355. doi:10.1002/pat.1995.220060514

Gruber E, Gruber R (1981) Viskosimetrische Bestimmung des Polymerisationsgrades von Cellulose. Das Papier 35(4):133-141

Helbert W, Cavaille JY, Dufresne A (1996) Thermoplastic nanocomposites filled with wheat straw cellulose whiskers 1. Processing and mechanical behavior. Polym Compos 17(4):604-611. doi:10.1002/pc.10650

Herrick FW, Casebier RL, Hamilton JK, Sandberg KR (1983) Microfibrillated cellulose: morphology and accessibility. J Appl Polym Sci Polym Symp 37:797-813

Ho T, Ko Y, Zimmermann T, Geiger T, Caseri W (2012) Processing and characterization of nanofibrillated cellulose/ layered silicate systems. J Mater Sci 47:4370-4382. doi:10. 1007/s10853-012-6291-8

Iotti M, Gregersen Ø, Moe S, Lenes M (2011) Rheological studies of microfibrillar cellulose water dispersions. J Polym Environ 19(1):137-145. doi:10.1007/s10924-010-0248-2

ISO (2004) Pulps-determination of limiting viscosity number in cupriethylenediamine (CED) solution. ISO 5351

Iwamoto S, Nakagaito AN, Yano H, Nogi M (2005) Optically transparent composites reinforced with plant fiber-based nanofibers. Appl Phys A Mater 81(6):1109-1112. doi:10. 1007/s00339-005-3316-z

Iwamoto S, Nakagaito AN, Yano H (2007) Nano-fibrillation of pulp fibers for the processing of transparent nanocomposites. Appl Phys A Mater 89(2):461-466. doi:10.1007/ s00339-007-4175-6

Jämsä S, Kataja K, Takala S, Putkisto K, Vastamäki P, Dyhr H (2010) Method for manufacturing paint or varnish. WO2011124759 A1

Karppinen A, Saarinen T, Salmela J, Laukkanen A, Nuopponen M, Seppälä J (2012) Flocculation of microfibrillated cellulose in shear flow. Cellulose 19(6):1807-1819. doi:10. 1007/s10570-012-9766-5 
Klemm D, Kramer F, Moritz S, Lindström T, Ankerfors M, Gray D, Dorris A (2011) Nanocelluloses: a new family of naturebased materials. Angew Chem Int Edit 50(24):5438-5466. doi:10.1002/anie.201001273

Koleske JV (ed) (2012) Paint and coating testing manual. 15th edn. ASTM International. doi:10.1520/MNL17-2ND-EB

Landry V, Blanchet P (2009) Coatings containing nanocrystalline cellulose, processes for preparation and use thereof. WO2011075837 A1

Lasseuguette E, Roux D, Nishiyama Y (2008) Rheological properties of microfibrillar suspension of TEMPO-oxidized pulp. Cellulose 15(3):425-433. doi:10.1007/s10570007-9184-2

Lopez-Suevos F, Eyholzer C, Bordeanu N, Richter K (2010) DMA analysis and wood bonding of PVAc latex reinforced with cellulose nanofibrils. Cellulose 17(2):387-398. doi:10.1007/s10570-010-9396-8

Lowys MP, Desbrières J, Rinaudo M (2001) Rheological characterization of cellulosic microfibril suspensions. Role of polymeric additives. Food Hydrocolloid 15(1):25-32. doi:10.1016/s0268-005x(00)00046-1

Martins N, Freire C, Pinto R, Fernandes S, Pascoal Neto C, Silvestre A, Causio J, Baldi G, Sadocco P, Trindade T (2012) Electrostatic assembly of Ag nanoparticles onto nanofibrillated cellulose for antibacterial paper products. Cellulose 19(4):1425-1436. doi:10.1007/s10570-0129713-5

Mezger TG (2011) The rheology handbook. European Coatings Tech Files, 3rd edn. Vincentz Network, Hanover

Molenaar F (1997) Rheological behaviour of latexes in-can and during film formation. Prog Org Coat 30(3):141-158

Nevell TP, Zeronian SH (eds) (1985) Cellulose chemistry and its applications. Halsted Press, Wiley, New York

Pääkkö M, Ankerfors M, Kosonen H, Nykänen A, Ahola S, Österberg M, Ruokolainen J, Laine J, Larsson PT, Ikkala O, Lindström T (2007) Enzymatic hydrolysis combined with mechanical shearing and high-pressure homogenization for nanoscale cellulose fibrils and strong gels. Biomacromolecules 8(6):1934-1941. doi:10.1021/bm061215p

Philipp C (2010) The future of wood coatings. Eur Coat J $1: 18-27$

Ridgway C, Gane PC (2012) Constructing NFC-pigment composite surface treatment for enhanced paper stiffness and surface properties. Cellulose 19(2):547-560. doi:10.1007/ s10570-011-9634-8
Ruiz MM, Cavaillé JY, Dufresne A, Graillat C, Gérard J-F (2001) New waterborne epoxy coatings based on cellulose nanofillers. Macromol Symp 169(1):211-222. doi:10. 1002/1521-3900(200105)169:1<211:aid-masy211>3.0.co; 2-h

Saarikoski E, Saarinen T, Salmela J, Seppälä J (2012) Flocculated flow of microfibrillated cellulose water suspensions: an imaging approach for characterisation of rheological behaviour. Cellulose 19(3):647-659. doi:10.1007/s10570012-9661-0

Saarinen T, Haavisto S, Sorvari A, Salmela J, Seppälä J (2014) The effect of wall depletion on the rheology of microfibrillated cellulose water suspensions by optical coherence tomography. Cellulose. doi:10.1007/s10570-014-0187-5

Saito T, Nishiyama Y, Putaux J-L, Vignon M, Isogai A (2006) Homogeneous suspensions of individualized microfibrils from TEMPO-catalyzed oxidation of native cellulose. Biomacromolecules 7(6):1687-1691. doi:10.1021/bm060154s

Spinu M, Santos N, Le Moigne N, Navard P (2011) How does the never-dried state influence the swelling and dissolution of cellulose fibres in aqueous solvent? Cellulose 18(2): 247-256. doi:10.1007/s10570-010-9485-8

Tingaut P, Zimmermann T, Lopez-Suevos F (2010) Synthesis and characterization of bionanocomposites with tunable properties from poly(lactic acid) and acetylated microfibrillated cellulose. Biomacromolecules 11(2):454-464. doi:10.1021/Bm901186u

Turbak AF, Snyder FW, Sandberg KR (1983) Microfibrillated cellulose, a new cellulose product: properties, uses, and commercial potential. J Appl Polym Sci Polym Symp 37:815-827

Wicks ZW, Jones FN, Pappas SP, Wicks DA (2006) Organic coatings. Wiley, Hoboken. doi:10.1002/9780470079072.ch5

Yano H, Sugiyama J, Nakagaito AN, Nogi M, Matsuura T, Hikita M, Handa K (2005) Optically transparent composites reinforced with networks of bacterial nanofibers. Adv Mat 17(2):153-155. doi:10.1002/adma.200400597

Zimmermann T, Pöhler E, Geiger T (2004) Cellulose fibrils for polymer reinforcement. Adv Eng Mater 6(9):754-761. doi:10.1002/adem.200400097

Zimmermann T, Bordeanu N, Strub E (2010) Properties of nanofibrillated cellulose from different raw materials and its reinforcement potential. Carbohydr Polym 79(4): 1086-1093. doi:10.1016/j.carbpol.2009.10.045 